\title{
COMMUNITY LEARNING WITH A 24/7 CHAT USING SMARTPHONES
}

\author{
Kimmo Vehkalahti and Matti Nelimarkka \\ University of Helsinki, Finland \\ Aalto University and University of Helsinki, Finland \\ kimmo.vehkalahti@helsinki.fi
}

Students say that Moodle is clumsy and too slow. They need faster channels for communications on a Data Analysis course, where they have to submit weekly reports for peer reviews. To enhance the interactions, we used an anonymized chat environment provided through Presemo software. This allowed students to use a regular web page on their smartphone, laptop or other internet connected devices, to instantly ask questions and answer them. The chat supports the community learning, as the students help each other while doing their exercises.

\section{INTRODUCTION}

Blended learning that combines traditional classroom teaching with various ways of using information and communication technology is an efficient method for teaching and learning of Data Analysis. In this paper, our focus is on a Data Analysis course where we use Moodle (Moodle Community 2015) for sharing materials and enabling discussions.

The outside classroom discussion in Moodle has not been very active. According to student feedback, Moodle is too slow and clumsy. It does not necessarily encourage them to communicate with their fellow students or with the teachers. The students are used to faster channels, like those provided by the social media platforms (Facebook, Twitter etc.) where they can discuss with their friends more easily using their smart phones, without the need of separately logging in to Moodle or other University specific platforms. Indeed, many students would be perfectly happy with a Facebook group, but it might be somewhat problematic from a teacher's point of view (cf. Deng \& Tavares, 2013). Firstly, students who are not in Facebook, may not be willing to be there, for various reasons. Secondly, a Facebook group might well attract not just outside classroom but outside course people, which might have interesting consequences. Thirdly, the regulations of a Finnish University might be in contradiction with those of an American social media platform. In addition, the student feedback indicates that the students would prefer asking their "stupid questions" anonymously instead of using their own name, which is the default setting in Moodle.

We have tried to answer these needs and enhance the interaction across the students with an anonymized chat environment provided through Presemo software that has been developed in the Helsinki Institute for Information Technology (HIIT 2015). This allows students to use a regular web page on their smartphone, laptop or other internet connected devices, to instantly ask questions and answer them, independent of time and place and without the need of logging in anywhere. Based on the experience of two implementations of the course, the results seem quite promising. The chat environment supports the community learning, as the students help each other while doing their exercises. In this paper, our focus is on the experiences from the course in 2014, when we tried the chat for the first time.

\section{APPROACH}

The course Data analysis with Survo and SPSS (5 ECTS credits, see EU 2015) runs for seven weeks and covers basic tasks of Data Analysis, such as building a data set from a text file, creating, re-coding and transforming variables, working with univariate graphs and statistics, forming and visualizing cross-tabulations, performing elementary statistical tests, and analyzing dependencies with simple linear regression models.

The skills of Data Analysis are learned and practised using two statistical software programs: Survo (Sund, Vehkalahti \& Mustonen 2012, Sund 2011, Mustonen 1992) and SPSS (IBM 2015). The students may choose whether they wish to learn Survo or SPSS (or both). The emphasis is mostly on Survo, as it is the long term research interest of the first author, and under an active development as an open source package for R (R Core Team 2013, Ihaka \& Gentleman 1996). SPSS is still supported, although its usage and need in the Faculty of Social Sciences is diminishing.

In: M.A. Sorto (Ed.), Advances in statistics education: developments, experiences and assessments. Proceedings of the Satellite conference of the International Association for Statistical Education (IASE), July 2015, Rio de Janeiro, Brazil. 
We utilize real-world data sets obtained primarily from the Finnish Social Science Data Archive (FSD 2015). In addition, we use selected open-access data sources, for example, Prices and earnings (UBS 2012) and Economic Freedom (Heritage Foundation 2015). Throughout the course, two essential and important, large-scale topics are emphasized: 1) the documentation of the work process (Vehkalahti 2005), and 2) the reproducible research (Gentleman \& Temple Lang 2007).

The course is organized as follows. Each week begins with a lecture (1.5 hours) on Tuesday morning at $8 \mathrm{am}$, where the idea is to present the goals and exercises of the week and briefly demonstrate the required technical phases. After the lecture, there are three alternative, voluntary computer classes (each 1.5 hours), two on the same day and one on Wednesday morning. They are supervised together by two assistant teachers, who have successfully completed the course one or two years earlier.

The number of students enrolled on the course has varied between 60 and 120 during the last five years. On the course of Spring 2014, there were about 90 students, who were either majoring or minoring in Statistics and had passed an elementary course of Statistics. This course is not compulsory for anyone, but it is recommended for the students of the Faculty of Social Sciences. In addition, there are several students from other Faculties of the University of Helsinki like Behavioural Sciences, Arts, Science, Medicine, Agriculture and Forestry, Biological and Environmental Sciences and their disciplines like Computer Science, Archeology, Chemistry, Mathematics, Geography, to name a few. All these and many more are connected by Data Analysis, which makes the course extremely interesting in its heterogeneity and richness.

Moodle (Moodle Community 2015) is used for delivering the materials, such as the data sets, the lecture files, and the exercises. It is also used for sharing the students' weekly reports and the assessment summaries, reminding the participants about the deadlines, informing of external topics related to the course content, and discussing the course matters in a Q\&A forum.

Each week, the students are supposed to write an individual report describing their workout with the exercises. The reports are submitted in a Moodle forum no later than Monday morning. They consist of 6-8 pages including text, tables, graphs, and program syntax. The general aim is to report the phases of the work process so that anyone on the course could follow and repeat them easily. All the reports are openly available for the participants as soon as they are submitted.

The reports are assessed by the students themselves during Monday (before the Tuesday lecture ends). Each student completes a self-assessment of her/his own report and does a peerreview of another report. The instructions of the peer-reviews are given in Moodle. The peer reviewers are chosen weekly by the teacher and listed in Moodle. Hence, everyone knows a couple of days in advance who is supposed to assess her/his report, so instead of any blind-review procedures the assessment is fully transparent.

Technically, the assessments are implemented using e-forms (Eduix 2015) and they consist of both numeric grades and textual reviews. We apply the general grading scale used at the University of Helsinki. It is a six-stage, non-proportionate scale as follows: 5 (excellent), 4 (very good), 3 (good), 2 (satisfactory), 1 (adequate), and 0 (fail). Each grade must be justified by a freeform explanation. The grade 0 (fail) is used only if the report has not been submitted. The assessments done by the students constitute a weekly data including two numerical grades and their textual supplements for every student. These data are almost automatically transformed from an Excel spreadsheet (saved from the e-form) into a compact report by the teacher using Survo, and the report is published in Moodle, usually on Wednesday. The final course grades are decided by the teacher and they are based on the weekly assessments and reports.

All the activities of the course and its hectic weekly schedule with tight deadlines generate much need for discussion, both inside and outside classroom. As the students do not seem to appreciate Moodle for quick discussions, we have tried to enhance the situation with an anonymized chat environment. This allows students to use a regular web page on their smartphone, laptop or other internet connected devices, to instantly ask questions and answer them, independent of time and place and without the need of logging in anywhere. 


\section{PRESEMO SOFTWARE}

Presemo is a web-based environment that allows real-time participation in classroom situation. The teacher can apply different types of interactive blocks to support participation, such as polls and chats. The primary use case in mind has been in-classroom use (e.g. Harry et al. 2009; Du et al. 2012, Birnholtz et al. 2013, Kohen 2014), however Nelimarkka et al. (2014) observed that elementary school students use it also outside classrooms. Similar observation of time and place independence have been previously made when examining chatting in workplace settings (Bradner et al. 1999).

From the users' perspective, the Presemo environment is easy to approach: it works on a web browser on any device, requires no registration to access the conversation and when accessed the interactive blocks are directly shown to the user. The chat block studied here allows the user to enter a message, which is then displayed below (see Figure 1). As the users are not identified, the messages do not have any identifying information related to them.

\section{An example of chat block}

\section{Send}

16:45 " Message 3

16:45 " Message 2

16:45 " Message 1

Figure 1. View from a Presemo chat block with three messages

\section{OUTCOMES}

The chat was used quite actively throughout the course, resulting in a total of ca. 1000 messages. Their length varied from a few words to almost 500 characters. A rough categorization of the topics would be: 1) questions related to Data Analysis or software programs, 2) answers to the questions (sometimes but not always by the teacher), 3 ) relaxed messages for lifting spirits.

The most active day (156 messages) was day \#1, when the chat was launched. As soon as the teacher gave the web address of the chat environment to the students, it took only a few seconds before there were over 60 students simultaneously testing the chat. After that, the chat activity followed the weekly schedule of the course, being most active before the report deadlines (see Figure 2). The two Sunday peaks on the weeks 4 and 5 are easy to explain, as those tend to be the most demanding weeks, and the report deadlines were on Monday mornings. 


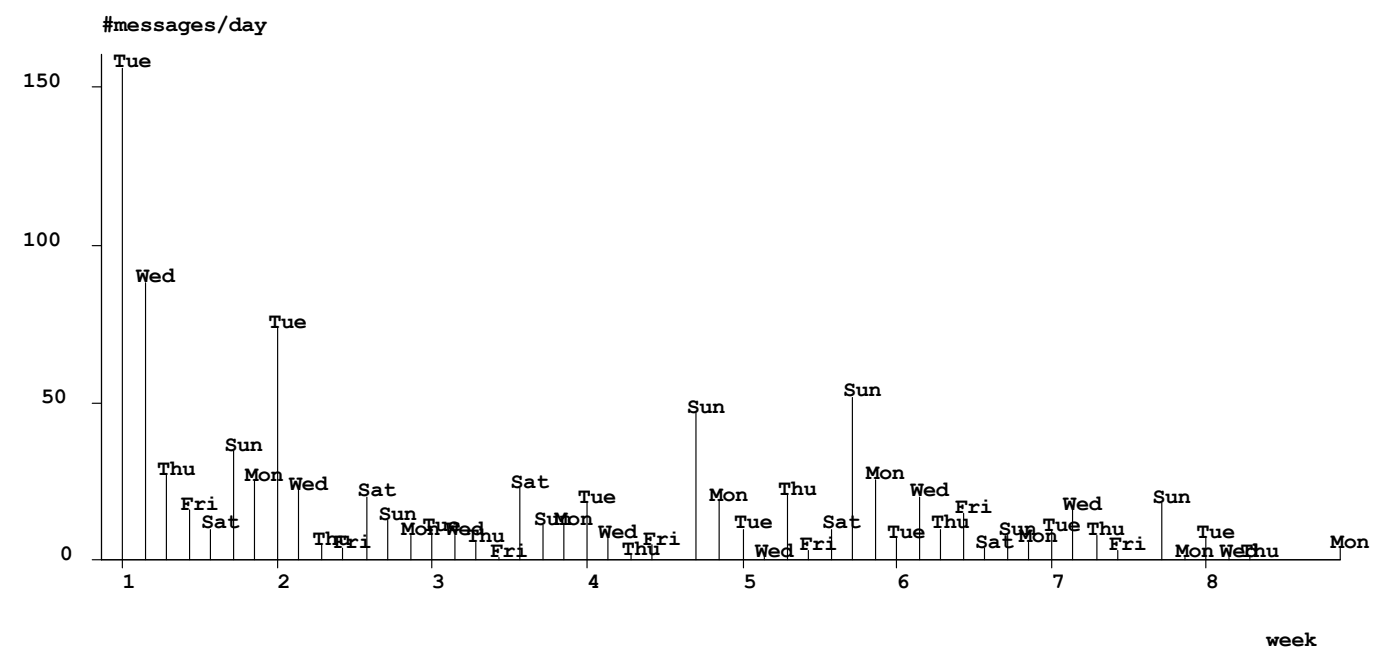

Figure 2. Number of daily chat messages during the course

Figure 3, where the message data has been aggregated by hour, shows the 24/7 nature of the course quite clearly. The chat was used most actively from 9 to 10 in the morning, probably because the peer-review deadline was on Tuesdays at 10 o'clock.

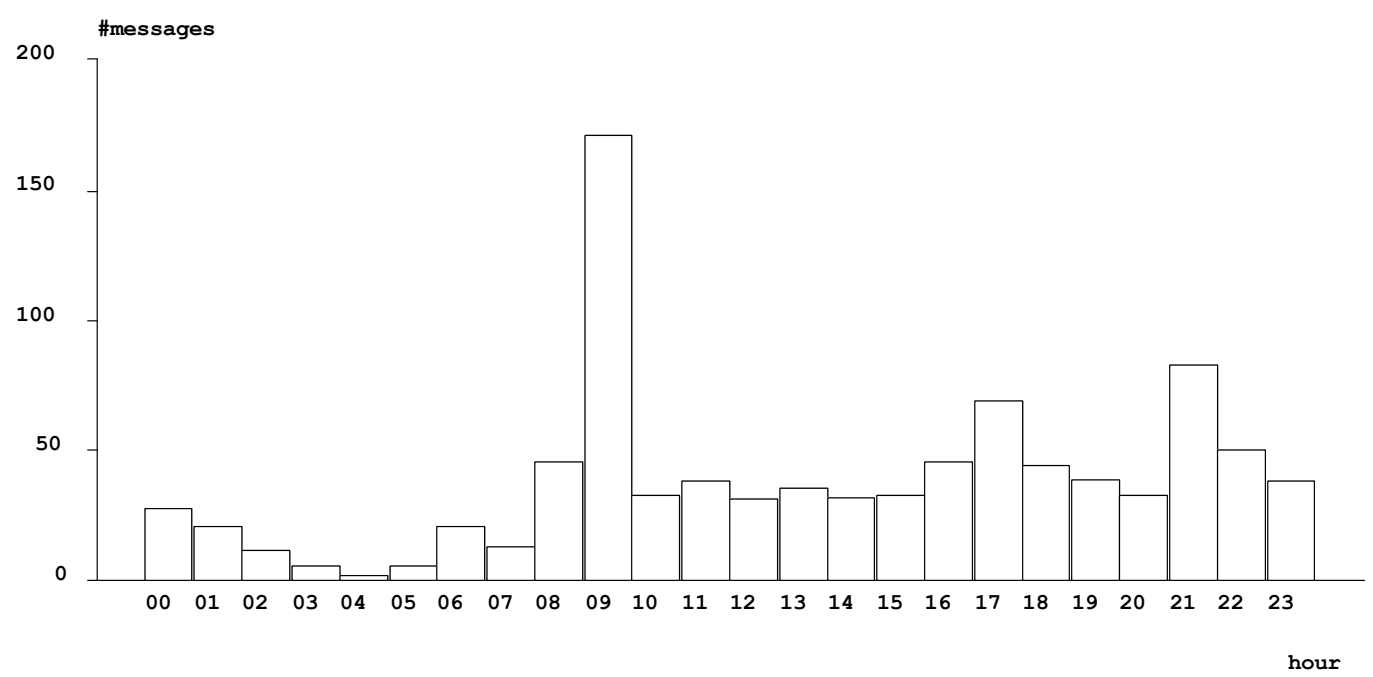

Figure 3. Number of chat messages by hour during the course

The anonymous chat enables the students to discuss the course topics in a fast pace and ask their "stupid" questions 24/7 without feeling stupid or shamed. Also, it is easy for them to answer to the other students' questions anonymously. We conclude that the anonymous chat supports the community learning, as the students help each other while doing their data analysis exercises.

\section{DISCUSSION}

Students say that they feel uncomfortable presenting "stupid" questions using their name (as is the common practice in Moodle). Furthermore, when technical problems with Survo or SPSS occur in the middle of the night, and the deadline is approaching in the morning, writing a message in the Moodle forum would be desperate: probably no one would even read it before the deadline. 
The anonymized chat environment provided through Presemo software has shown to be useful. The teacher may follow the chat discussions and sometimes write a message, too. However, quoting John Biggs, "it's not what the teacher does, it's what the student does" (Biggs, 2003). In the night time, when the teacher is (usually) sleeping, many students are wide awake. This is revealed immediately from the timestamps of the reports and the chat messages, cf. Figure 3. Luckily, there is no serious need for the teacher (at least not in the night time!), as the community of students is an excellent resource for help, encouragement, and peer support.

\section{ACKNOWLEDGEMENTS}

The authors are grateful for PhD Liisa Myyry, the senior lecturer in university pedagogy at the Faculty of Social Sciences at University of Helsinki, for her useful comments and suggestions.

\section{REFERENCES}

Biggs, J. (2003). Teaching for Quality Learning at University, Second edition, Open University Press.

Birnholds, J., Hancock, J., \& Retelny, D. (2013). Tweeting for Class: Co-Construction as a Means for Engaging Students in Lectures. In Proceedings of the SIGCHI Conference on Human Factors in Computing Systems - CHI '13, 797-800. doi:10.1145/2470654.2470767.

Bradner, E., Kellogg, W.A., \& Erickson, T. (1999). The Adoption and Use of 'BABBLE': A Field Study of Chat in the Workplace. In Proceedings of the Sixth European Conference on Computer Supported Cooperative Work, 139-158. doi:10.1007/978-94-011-4441-4_8. http://dl.acm.org/citation.cfm?id=351698.

Deng, L., \& Tavares, N.J. (2013). From Moodle to Facebook: Exploring students' motivation and experiences in online communities. Computers \& Education 68, 167-176.

Du, H., Rosson, M.B., \& Carroll, J.M. (2012). Augmenting Classroom Participation through Public Digital Backchannels. In Proceedings of the 17th ACM International Conference on Supporting Group Work - GROUP '12, 155-164. doi:10.1145/2389176.2389201. http://dl.acm.org/citation.cfm?id=2379057.2379081.

Eduix (2015). Browser based application for creating and managing e-forms. https://elomake.fi/web/briefly-in-english.html

EU (2015). European Credit Transfer and Accumulation System (ECTS). http://ec.europa.eu/education/tools/ects_en.htm

FSD (2015). Finnish Social Science Data Archive, Tampere, Finland. http://www.fsd.uta.fi/en/

Gentleman, R., \& Temple Lang, D. (2007) Statistical Analyses and Reproducible Research. Journal of Computational and Graphical Statistics, 16, 1-23.

Harry, D., Green, J., \& Donath, J. (2009). Backchan.nl. In Proceedings of the 27th International Conference on Human Factors in Computing Systems - CHI 09, 1361-1370. New York, New York, USA: ACM Press. doi:10.1145/1518701.1518907. http://dl.acm.org/citation.cfm?id=1518701.1518907.

Heritage Foundation (2015). Index of the Economic Freedom. http://www.heritage.org/index/

HIIT (2015). Presemo: a participation platform. http://www. hiit.fi/presemo

IBM (2015). SPSS: a predictive analytics software. http://www.ibm.com/software/analytics/spss/

Ihaka, R., \& Gentleman, R. (1996). R: A Language for Data Analysis and Graphics. Journal of Computational and Graphical Statistics, 5, 299-314.

Kohen, A. (2014). Tumbling Political Theory. Politics, doi:10.1111/1467-9256.12051.

Moodle Community (2015). Moodle: an open-source learning platform. https://moodle.org

Mustonen, S. (1992). Survo - An Integrated Environment for Statistical Computing and Related Areas. Survo Systems, Helsinki, Finland. (494 pp.) http://survo.fi/books/1992/Survo_Book_1992_with_comments.pdf

Nelimarkka, M., Kuikkaniemi, K., \& Jacucci, G. (2014). A Field Trial of an Anonymous Backchannel Among Primary School Pupils. In Proceedings of the 18th International Conference on Supporting Group Work - GROUP '14, 238-242. New York, New York, USA: ACM Press. doi:10.1145/2660398.2660399. http://dl.acm.org/citation.cfm?doid=2660398.2660399. 
R Core Team (2013). R: A language and environment for statistical computing. R Foundation for Statistical Computing, Vienna, Austria. http://www.R-project.org/.

Sund, R. (2011). Muste - the R implementation of Survo. In the yearbook of Finnish Statistical Society, pp. 133-146. http://www.survo.fi/muste/publications/sund2011_muste_yearbook.pdf

Sund, R., Vehkalahti, K., \& Mustonen, S. (2012). Muste - editorial computing environment within R. Proceedings of COMPSTAT 2012, 20th International Conference on Computational Statistics, 27-31 August 2012, Limassol, Cyprus. pp. 777-788. http://www.survo.fi/muste/publications/sundetal2012.pdf

UBS (2012). Prices and earnings. http://www.ubs.com/global/en/wealth_management/wealth_management_research/prices_earn ings.html

Vehkalahti K. (2005). Leaving useful traces when working with matrices. Research Letters in the Information and Mathematical Sciences 8, 143-154. Proceedings of the 14th International Workshop on Matrices and Statistics (IWMS 2005). 